University of Rhode Island

DigitalCommons@URI

Open Access Dissertations

1987

\title{
The Relationship Between Children's Observation of Marital Discord and Play Behavior in a Non-Clinical Sample
}

Dorothy Bohn Clement

University of Rhode Island

Follow this and additional works at: https://digitalcommons.uri.edu/oa_diss

\section{Recommended Citation}

Clement, Dorothy Bohn, "The Relationship Between Children's Observation of Marital Discord and Play Behavior in a Non-Clinical Sample" (1987). Open Access Dissertations. Paper 1035.

https://digitalcommons.uri.edu/oa_diss/1035

This Dissertation is brought to you for free and open access by DigitalCommons@URI. It has been accepted for inclusion in Open Access Dissertations by an authorized administrator of DigitalCommons@URI. For more information, please contact digitalcommons-group@uri.edu. 
THE RELATIONSHIP BETWEEN CHILDREN'S OBSERVATION

\author{
OF MARITAL DISCORD AND \\ PLAY BEHAVIOR IN A NON-CLINICAL SAMPLE \\ BY \\ DOROTHY BOHN CLEMENT
}

A DISSERTATION SUBMITTED IN PARTIAL FULFILLMENT OF THE REQUIREMENTS FOR THE DEGREE OF

DOCTOR OF PHILOSOPHY

IN

PSYCHOLOGY

UNIVERSITY OF RHOIJE ISLANI)

1987 
Abstract

The present investigation examined the relationship between children's exposure to low to moderate rates of marital discord in the familial environment and their behavior in settings external to the home as assessed by adult raters and direct observations. sixty children (36 males, 24 females) between the ages of 6 and 13 years were estudied over the course of 3 months. Results of a multi-step analysis indicated that there was a highly significant relationship among females of low ses status between exposure to marital discord at home and being the object of peer aggression during free play activity. A significant relationship was also found between exposure to marital discord at home and externalizing behavior problems (aggression towards peers) for subsamples of male children in the present study who were younger and less intelligent. The implications of these results for understanding the complex factors affecting the relationship between marital discord and childrens' behavioral disturbances are discussed. 


\section{ACKNOWLEDGEMENTS}

This dissertation is the product of over three years and many hours of work. I would like to thank my major professor, Dr. Mark Rapport, who spent countless hours editing and leading this dissertation, and Dr. Richard Pollnac, whose positive attitude, genuine interest in me and mastery of the computer, made work with statistics almost fun. I would also like to express my appreciation to Dr. Alan Willoughby for his support in both this dissertation and in life, and to Dr. Richard Gelles, whose expertise in the field of family violence helped me focus this project.

Many friends and family have also supported me and encouraged me throughout my studies. I would especially like to thank Mr. Steven Cerbo and Mr. William Brown, who patiently listened to my doubts. A special thanks also to Mr. Robert Mattis for his support and help printing this dissertation.

Many camps, schools and volunteers helped by their participation in this project. These include Moses Brown Camp, Brown summer Camp, Rhode Island College Camp, Camp Wohelo, and st. Theresa's parochial school. Their cooperation and the cooperation of the children and parents of these camps and school, made this dissertation possible. 


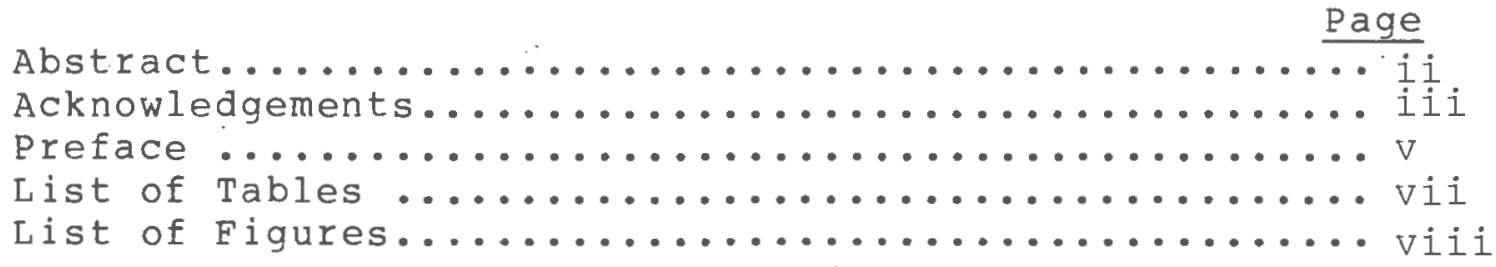

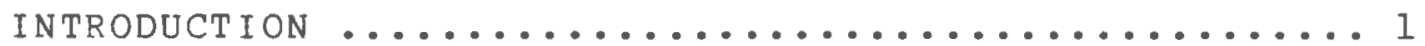

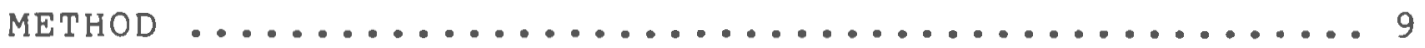

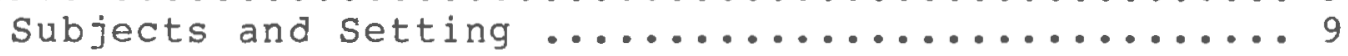

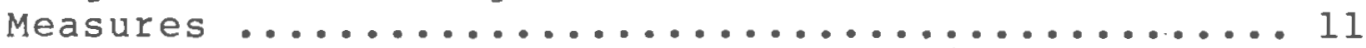

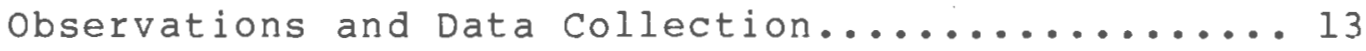

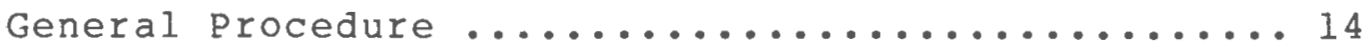

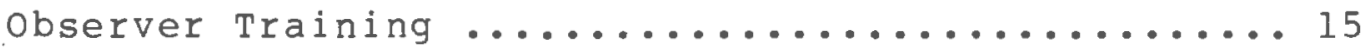

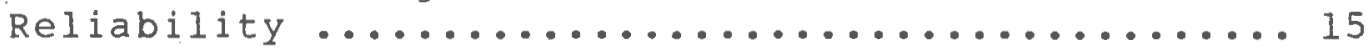

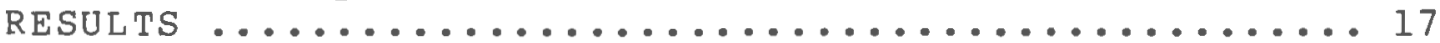

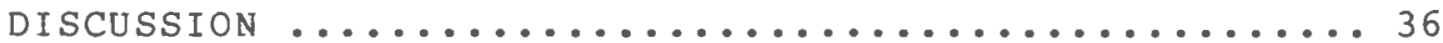

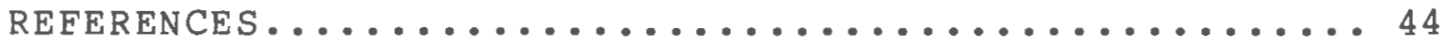

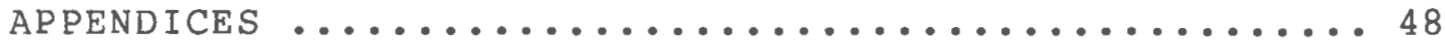

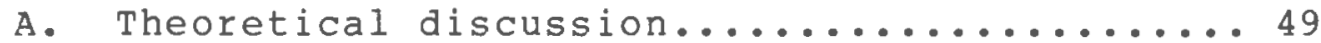

B. Peabody Picture Vocabulary Test ............ 51

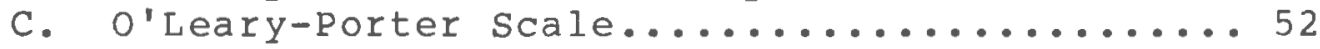

D. Hollingshead Two Factor Index of Social Position............................ 53

E. Walker Problem Identification Checklist..... 55

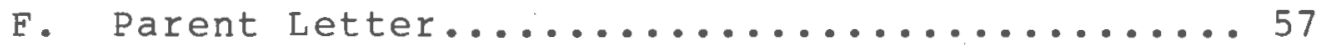

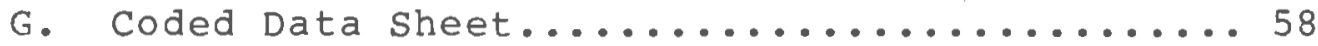




\section{PREFACE}

The following dissertation is written in the manuscript format. Section 1 contains the complete journal article. Section 2 contains details of the instrumentation and data. 


\section{LIST OE TABLES}

\section{TABIE}

$\underline{P A G E}$

1. Breakdown of Sexes by Socioeconomic Catagories ...10

2. Sumary Statistics from Regression Analyses......18

3. Means and standard Deviations of each Variable...2

4. Correlation between Marital Discord and Dependent Variables for all groups and males and females....21

5. Correlation Matrix of Marital Discord and

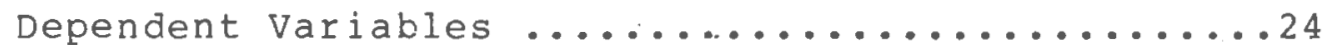

6. Partial Correlations between Marital Discord

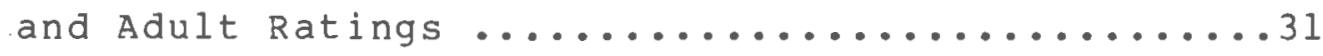

7. Pearson Product Moment Correlations between Marital Discord and Male's Behavior and Ratings on the Walker Checklist divided into

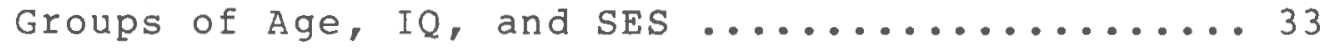

8. Pearson Product Moment Correlations between Marital Discord and Female's Behavior and Ratings on the Walker Checklist divided into Groups of Age, IQ, and SES ................ 34 


\section{LIST OF FIGURES}

\section{Eigure}

1. Scatterplot of the Predicted Shape of the Relationship between Marital Discord and object of Aggression for Females...............28 
SECTION I

viii 
The Relationships between Children's Observation of Marital Discord and Play Behavior in a Non-Clinical Sample

Marital discord and its possibly negative influence on children has been a frequently debated and often controversial topic of public concern over the past several years. Not unexpectedly, there is a clear gap between the information alluded to in these discussions and existing empirical knowledge. At present, the information regarding the relationship between marital discord and its effect on children's behavior is relatively sparse, generally inconclusive, and far from monolithic. Nevertheless, several studies have recently examined the relationship between marital discord and childhood psychopathology in both clinic (oltmanns, Broderick, \& O'Leary, 1977; Rutter, 1971) and non-clinic (Block, Block, \& Morrison, 1982; Emery \& O'Leary, 1984) populations.

The scientific study of marital discord presents numerous problems. One problem is finding a definition of the phenomenon which can be accepted by both clinicians and reseachers. Definitions have ranged from an emphasis on physical abuse to a broad focus on the amount of disagreement that occurs within a family. The definition used in this study was to examine 
marital discord broadly along a continuum. This definition includes all disagreement, arguing, and/or physical aggression which occurs between the parents in the family. Conceptualizing marital discord within this framework allows one to investigate quantitative differences in children's behavior as it relates to the frequency of marital discord in the family.

A second problem is that the relationship between marital discord and children's behavior problems depends, in part, on the composition of the population studied. For example, among the clinic population studies, there is a general concensus that problems of undercontrol in male children (e.g., antisocial behavior) are associated with discordant marriages and that the extent of these problems may be exacerbated by such factors as the severity (Rutter et al., 1975) or longevity (Rutter, 1980) of discord and whether the child (Johnson \& Lobitz, 1974 ) or parent (Emery, Weintraub, \& Neale, 1982) has been referred for psychological treatment. Conversely, severe childhood problems are relatively infrequent in families reporting little or no discord (Emery et al., 1982) leading some to suggest that marital discord and childhood psychopathology are reciprocally influencing factors (Lerner \& Spanier, 1978), precursors to one another (O'Leary \& Emery, 1983), or marker variables of 
biological susceptibility (Rutter, 1970).

Curiously, there is a dearth of information regarding the relationship between the behavior of nonclinic populations of children and marital discord (cf. O'Leary \& Emery, 1983, for a review). The results of the few studies conducted to date are largely equivocal owing to a variety of methodological problems such as (1) the use of unreliable measures (e.g., Whitehead, 1979); (2) a failure to obtain independent ratings or direct observations of child behavior problems (e.g., Porter, 1981); (3) a failure to control for rater biases (e.g., Ferguson \& Allen, 1978); and (4) a reliance on retrospective methods of data collection (e.g., Kalmuss, $1984)$.

Several important questions regarding the relationship between marital discord and childhood behavior are yet unanswered. For example, in the few studies of marital discord which used two raters, there has been lack of agreement between parent and teacher ratings of children's behavior (Emery \& O'Leary, 1984). Expectation bias (Rosenthal, 1966) or situation specific behavior have been used to account for these differences (cf. Emery, 1982, for a review). That is, children may either act or be perceived differently in different settings. Discordant families may perceive their 
children more negatively (Griest, Forehand, \& Wells, \& McMahan, 1980), thus inflating the relationship between marital discord and childhood behavior pathology. Conversely, teacher ratings of children may be less sensitive to differences in children's behavior unless it is displayed in the classroom. The validation of the mothers' and/or teachers' reports of children's behavior through the use of behavioral observations is essential to determine if differences exist in the behavior of children exposed to mild to moderate levels of discord and the behavior of children not exposed to discord.

A second question involves gender differences and the manner in which males and females respond to marital discord. For example, in clinic samples, conduct problems of boys generally have the highest association with marital discord, whereas little or no relationship is found between marital discord and girls' behavior (Porter \& O'Leary, 198ø; Rutter, 1970). In non-clinic samples, gender differences are generally less well understood. When gender differences are found, boys generally respond to discord with more maladaptive problems of undercontrol and girls respond with less noticeable problems of overcontrol (Block et al., 1981). Associations between marital discord and problems of undercontrol are consistently reported, whereas findings 
for problems of overcontrol are variable.

Finally, the impact of the child's age, intelligence, and socioeconomic status on the relationship between childhood behavior and marital discord is unknown. At present, little can be concluded except that these may be critical variables of interest for which convincing data have not been presented.

Behaviors observed in the family can be learned and subsequently modeled in other environments (Bandura, 1969). Thus, children exposed to marital discord may model the aggressive behaviors they observe (see Appendix A). Children are more likely to imitate a same sex model (Margolin \& Patterson, 1975). Since husbands act more overtly and severely aggressive than wives during times of marital discord (Straus, 1978), differential imitation of this interaction may lead to gender differences. Specifically, aggressive behavior may be observed more frequently in males, whereas withdrawal from social interaction and/or being the target of aggressive behavior may be frequent in females. The primary purpose of the present study is to examine whether low to moderate rates of marital discord are related to childhood behavior in a non-clinic sample of children. A second purpose was to investigate the relationship between adult ratings and direct 
observations of children's behavior and their relationship to marital discord. A third purpose was to examine the effect of moderator variables such as the child's gender, age, intelligence and socioeconomic status on the relationship between children's behavior and marital discord.

First Hypothesis: Parental discord in the home is associated with behavior disorders (aggression) in children.

Predictions:

1. It was predicted that children whose mothers reported high rates of marital discord in the home would be rated high on factor 1 (acting out) of the Walker Problem Identification Checklist.

2. It was predicted that children whose mothers reported high rates of marital discord in the home would display more inappropriate aggressive behavior during free play.

Second Hypothesis: Parental discord in the home differentially affects boys and girls observing it. Predictions:

1. It was predicted that boys whose mothers reported high frequencies of discord on the o'Leary-Porter scale (Porter \& O'Leary, 1980) would be rated high by their teachers/counselors high on factor 1 (acting out) of the 
Walker Problem Identification Checklist (Walker, 1976). Boys whose mothers reported them as observing low frequencies of discord would be rated low on factor 1 of the Walker Problem Identification Checklist.

2. It was predicted that boys whose mothers reported high frequencies of discord on the o'Leary-porter scale, would exhibit more overt aggressive behavior with their peers as rated by behavioral observations taken in a free play or play situation. Boys whose mothers reported them as observing low frequencies of discord on the O'Learyporter scale, would exhibit less overt aggressive behavior with their peers as rated by behavioral observations taken in a free play or play situation. 3. It was predicted that girls whose mothers reported high frequencies of discord on the o'Leary-Porter scale would be rated by their teachers/counselors high on factor 2 (withdrawal) of the Walker Problem. Identification Checklist. Girls whose mothers reported them as observing low frequencies of discord would be rated low on factor 2 of the walker problem Identification Checklist.

4. It was predicted that girls whose mothers reported high frequencies of discord on the o'Leary-Porter scale would exhibit more isolated behavior as rated by behavioral observations taken in a free play or play 
situation. Girls whose mothers reported them as observing low frequencies of discord on the o'LearyPorter scale would exhibit low rates of isolated behavior as rated by behavioral observations taken in a free play or play situation.

5. It was predicted that girls whose mothers reported high frequencies of discord on the o'Leary-porter scale would be the target of aggression as rated by behavioral observations taken in a free play or play situation. Girls whose mothers reported them as observing low frequencies of discord on the O'Leary-Porter Scale would not be the target of aggression in a free play or play situation. 
Method

Subjects and setting

Sixty children were selected from five summer camps and a parochial school in various parts of southern New England to participate in the study. All participants were volunteers whose mothers completed a questionnaire regarding the amount of marital discord the children observed in the home and gave permission to have their children included in the study. The children were selected from families in which the father was the primary male involved with the child. The children ranged in age from 6 to 13 years $(M=9.75$ years; $S D=1.6$ years). An attempt was made to obtain a sample which represented all levels of socioeconomic status (SES) by choosing subjects from typically lower, middle and upper SES areas of southern New England. Socioeconomic status was determined by the mother's completion of the Hollingshead Two Factor Index of social position. The specific breakdown of males and females into socioeconomic categories can be seen in Table 1 . There were no male children in the lowest socioeconomic category. 
Table 1

Summary of Socioeconomic Categories by sex

$\begin{array}{cccc}\text { Category } & \text { Total } & \text { Males } & \text { Females } \\ 1 & 4 & 2 & 2 \\ 2 & 18 & 14 & 4 \\ 3 & 22 & 15 & 7 \\ 4 & 13 & 5 & 8 \\ 5 & 3 & 0 & 3\end{array}$


Three camps were located in urban, upperclass neighborhoods, one was in a rural, middleclass area, and the remaining camp and parochial school were located in urban, lower socioeconomic area. An investigation of the camp and school rosters indicated that the majority of children attending these settings lived in nearby neighborhoods.

The Peabody Picture Vocat : (PPVT-R; Dunn \& Dunn, 1981) (see Appendix B) was administered to each child as a screening procedure to insure that all children participating in the study were of average and above average intelligence ( $M=105.98$; $S D=15)$. The PPVT-R is an individually administered, norm-referenced, wide-range, power test of 1 istening vocabulary. Reliability and validity are both sufficiently high for group classification and are documented in Dunn and Dunn (1981).

Counselors and teachers participating in the study were employed at the camps and school and ranged in age from 18 to 50 years $(\underline{M}=27$ years).

\section{Measures}

The mothers of participating children were asked to complete the o'Leary-Porter scale (OPS; Porter \& O'Leary, 1980), a 10 item (9 scored plus one unscored item) instrument developjd as a face valid measure of openly 
expressed mirital conflict (see Appendix C). The ops has been show to zorrelate moderately with the short Marital Adjustment Test (Lock \& Wallace, 1959) and to have high test-retest reliability (Porter \& O'Leary, 1980).

Socioeconomic status was based on the overall SES of the children's parents as determined by the Hollingshead's Two Factor Index of Social position (Hollingshead, 1957). The Hollingshead Two Eactor Index of Social position is a modified form of the Alba Edwards' system of classifying occupations into socioeconomic groups employed by the U.S. Bureau of Census. The scale used in the Index of Social positon ranks professions into different groups and businesses according to their size and value. (see Appendix D).

Counselors and teachers of each child participating in the study were requested to complete the walker Problem Behavior Identification Checklist (WPBIC; Walker, 1976) to assess aggression and isolation in children. The checklist is designed for use in the elementary grades $(\mathrm{K}-6)$ and is composed $\mathrm{c}$ : observable, operational statements regarding children's behavior (see Appendix E). The WPBIC contains ave sub-scales: Acting-out, Witharawal, Distractibility, Disturbed Peer Relations and Immaturity, which $b$ : ve been found to be relatir Iy independent of one another (Walker, 1976). 
Test-retest coefficients are available for scale scores from preschool to grade six. Total score stability coefficients approximate .80 across separate studies and samples (Walker, 1983 ).

Observations and Data collection

Observational data for the study were collected in five summer camps and one parochial school during regularly scheduled sessions of non-academic, free-play time. All data were collected during a 6 to 9 month period.

Multiple behavior ratings were used to assess children's behavior during free-play periods as described below:

Aggression. This category included any and all verbal or physically assaultive, taunting, obstructive or threatening behavior including striking, slapping, tripping, kicking, pushing or pulling others. Aggression was coded as either Ao, meaning the child was the object of aggression, or Ai, meaning the child initiated the aggression with a peer or group of peers.

Isolate Activity. This category included any activit, displayed by the child when (s) he was not in the phyical proximity of others for at least $15 \mathrm{~s}$. This behavioral rating category was not scored if the child was involved in any orgarized play which required being 
alone (e.g., standing on second base in a baseball game, talking to distant children or adults).

General procedure. Letters asking for consent to participate in the study were sent home to all parents of children ages 6-13 years who attended the camps and school. (see Appendix F). The parents were asked to return the consent form and to complete the o'Leary Porter Scale and the Hollingshead Two Factor Index. Results from the questionnaire were loaded by code number (blindly) into the University of Rhode Island computer data files.

A coded data sheet was developed to facilitate data collection and the assessment of observer agreement (see Appendix G). The data sheet was composed of 150 blocks, with each block containing the three behavior codings.

Each child was observed for a total of $60 \mathrm{~min}$ across a four to six week period. In conducting the observations, one child was observed for a 5 min interval which was divided into $3 \emptyset \mathrm{s}$ behavior samples. Each $3 \emptyset \mathrm{s}$ sample was divided to allow for $20 \mathrm{~s}$ of observation, followed by 10 s for recording. One child was observed for a 5 min interval before observing another child in a particular setting. The observations continued until each child was observed for a total of at least $6 \emptyset$ minutes over a three mor h perior. 
In those cases when behaviors began in one $30 \mathrm{~s}$ interval and continued into the next, they were marked as occurring in both intervals provided they met the aforementioned coding criteria. It was possible to code more than one behavior during each $30 \mathrm{~s}$ behavior sample.

\section{Observer Training}

Ten college undergraduate students and the primary investigator served as data collectors. All observers were required to famii.: "ize themselves with the behavioral definitions and observational procedures. Prior to beginning formal data collection, each observer was required to demonstrate at least 80 percent overall agreement with the primary investigator based on five consecutive, 5 min sessions using non-participating children. All observers except the primary investigator were blind to the specific reason and nature of the study.

$\underline{\text { Reliability }}$

Each $3 \emptyset$ s interval on the coding sheet was scored for agreement (see Appendix G). Occurrence, nonoccurrence and chance estimates were calculated for each child across behavioral categories (Kazdin, 1982). During the course of the study, observer agreement was 
assessed on $33 \%$ of the total number of $5 \mathrm{~min}$ observational sessions (i.e.,29 min for each child). Interobserver reliability estimates were generally high (group mean = 79웅 reliability; group kappa=.44 reliability). 
Results

Multiple regression analyses (MRA) using an all ways format were performed to examine the relationships between the independent variables (marital discord, age, IQ and SES of the child) and the dependent variables (aggression initiated at free play (Ai), aggression object at free play (Ao), isolation at free play (I), Teacher and counselor ratings of aggression and withdrawal on the Walker Problem Behavior Identification Checklist. The results of the analyses showed several significant relationships. For the dependent variable Ao, (object of aggression), marital discord was significant, $\underline{E}(1,58)=3.27, \underline{p}<.05$, but accounted for only a small proportion of the variance (i.e., 7\%). Socioeconomic status was also significant, $\underline{E}(1,58)=$ 7.54, pe. 01 , and accounted for a modest proportion of the variance (i.e., 9\%).

For the dependent variable I (isolation), IQ was significant, $\underline{E}(1,58)=5.73, \underline{p}<.05$, but also explained only a small proportion of the variance (i.e., 9\%). For the variables aggression initiated (Ai), walker factor 1 (Acting-out), walker factor 2 (withdrawal), and the Total walker Pathology score, no significant variance was accounted for by the independent variables. 
Table 2

Summary Statistics from Regression Analyses and

Significant Variables

Dependent Variables

Aggression

object
Aggression

Initiated
Isolate

behavior

\section{Independent}

variables df

R 2

R2

R 2

Marital 1,58

$.07 *$

.04

.903

Discord

SES

1,58

$.09 *$

.02

.001

IQ

1,58

.0094

.001

$.09 *$

AGE

1,58

.$\emptyset \emptyset 4$

.92

.99096

\section{Dependent Variables}

Walker A

Factor 1
Walker $B$

Factor 2
Total

Walker score

Independent

variables

df

R 2

R2

Marital

Discord

$\begin{array}{lcccc}\operatorname{SES} & 1,58 & .0 \emptyset 5 & .0 \emptyset 4 & . \emptyset \emptyset 9 \\ \text { IQ } & 1,58 & . \emptyset 1 & . \emptyset \emptyset 2 & .0 \emptyset 4 \\ \text { AGE } & 1,58 & .0 \emptyset 4 & . \emptyset 4 & .03 \\ \star=p<.05 & & & & \end{array}$


Insert Table 2 about ‘ere

Due to the relatively modest relationships obtained in the MRA between marital discord and the dependent variables (see Table 2), an Analyses of Variance (ANOVA, BMDP7D program) using a welch Brown-Eorsythe test statistic (Brown \& Forsythe, 1974) was conducted to determine if the total population might be more heterogeneous than initially hypothesized. Based on previous research in clinic populations which indicated that differences might be observed in the way in which males and females responded to marital discord, (cf. Porter \& O'Leary, 1980), gender differences were examined for each of the independent and dependent variables and Pearson product moment correlation coefficients between marital discord and the dependent variables for the total population and for males and females were calculated. The . 05 level of significance was selected a priori to conducting this analysis.

\section{Insert Table 3 and 4 about here}

For the independent variables, a significant difference was found only for socioeconomic status (SES), indicating that the male subsample came from households 
Table 3

Means and Standard Deviations of each Variable

Independent Variables

Age

(in months) 117

IQ

SES * *

Discord

Range

$(9-43)$
Tota1

$\overline{\mathrm{X}} \quad \mathrm{SD}$

$\frac{\text { Males }}{\mathrm{X}}$

$118 \quad 2 \emptyset$

$107 \quad 14$

$2.6 \quad .79$

$18 \quad 6.5$

186.3

6.3
Females

$\overline{\mathrm{X}} \quad \mathrm{SD}$

$115 \quad 15$

$1 \emptyset 4 \quad 14$

3.31 .1

186.0

Dependent Variables

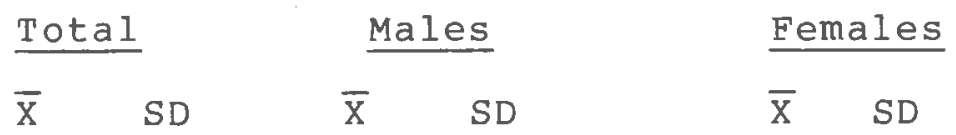

$\begin{array}{lllllll}\begin{array}{l}\text { Aggression } \\ \text { Initiated }\end{array} & 2.4 & 3.8 & 3.2 & 4.6 & 1.2 & 1.7 \\ \begin{array}{l}\text { Aggression } \\ \text { Object }\end{array} & 1.6 & 2.3 & 1.9 & 2.6 & 1.2 & 1.6\end{array}$

Isolation

$17.7 \cdot 14.7$

$18.6 \quad 16.8$

16.4

$53.3 \quad 12.1$

Walker

Factor 1

Walker

$51.8 \quad 10.5$

$48.4 \quad 7.4$

49.1

8.5

$50.4 \quad 11.7$

Total Walker $5 \emptyset \quad 9.9$

score

$\star=<. \emptyset 5 ; \star \star=<. \emptyset 1$ Welch Brown-Eorsythe one Way Analysis of Variance for Within Group Variance not Assumed to be Equal 
Table 4

Correlation Matrix of Marital Discord for all groups and Males and Females
A11 groups
Males
Females

Dependent variable

\begin{tabular}{lccc} 
aggression object & $.29 *$ & .17 & $.65 * * *$ \\
aggression initiated & .23 & .28 & .17 \\
isolation & -.14 & -.24 & .10 \\
Walker Factor 1 & .098 & -.08 & .27 \\
Walker Factor 2 & -.92 & -.02 & .01 \\
Walker Total & .01 & -.08 & .30 \\
\hline
\end{tabular}

$\star=\mathrm{p}<.05 ; \quad * \star=\mathrm{p}<.01 ; * \star \star=\mathrm{p}<.001$ 
of higher income and/or educatior $\underline{F}(1,58)=5.12$, $\underline{p}<.65$. The difference between males and females was due to a lack of males in the lowest SES bracke.

A difference was also observed betw en the subsample of males and females on the dependent variables in the amount of aggression initiated (Ai) in free-play settings, with males displaying significantly more aggression than females, $\underline{F}(1,58)=5.34, \underline{p}<.05 . A$ complete listing of means and standard deviations of the independent and dependent variables is depicted in Table 3 for the total group and gender subsamples.

A further analysis of the correlation coefficients for the total group and for males and females separately, revealed that males and females differed markedly in their responses to marital discord (see Table 4). Given the significant differences found in the between-gender comparisons across the various independent and dependent variables, the two subsamples were examined separately using Pearson product moment correlations. The Relationship Between Marital Discord and Observed Behavior and Adult Ratings

A primary purpose of the present investigation was to determine what relationship, if any, exists between childrens' observation of marital discord in the familial environment and their overt behavior as observed and 
reported in other settings. To examine this relationship, a correlation matrix (see Table 5) was constructed using the index of marital discord completed by each child's mother (i.e., O'Leary-porter scale), observational data of zhildren's behavior in free-play settings (i.e., recorded frequencies of child-initiated aggressive behavior, isolation behavior, and aggressive behavior directed towards the child by other children), and teacher or counselor's ratings of children's behavior (i.e., Factor 1-Acting out, Factor 2- withdrawal, and Total Pathology score on the walker Checklist).

\section{Insert Table 5 about here}

As depicted in Table 5, the relationship between children's observations of marital discord in the familial environment and their behavior in externally rated or observed settings was differentially affected according to the child's gender. Moreover, the various relationships found for males and females were frequently quite different. For example, the relationship between observing marital discord at home and being the object of other children's aggression in free-play settings was significant $\underline{r}(24)=.64$, $\underline{p}<\emptyset \emptyset 1$ for females and accounted for a relatively 
Table 5

Correlation Matrix of Marital Discord and Dependent Variables

Marital Walker Walker Walker

Discord Factor 1 Eactor 2 Total

\begin{tabular}{|c|c|c|c|c|c|c|c|c|}
\hline & $M$ & $\underline{E}$ & $M$ & $\underline{F}$ & $M$ & $\underline{F}$ & $M$ & $\underline{\mathrm{E}}$ \\
\hline $\begin{array}{r}\text { Aggression } \\
\text { object }\end{array}$ & .17 & 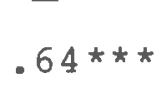 & $.35 *$ & .14 & -.02 &.$- \emptyset 2$ & .17 & .08 \\
\hline $\begin{array}{l}\text { Aggression } \\
\text { Initiated }\end{array}$ & .28 & .17 & $.40 *$ & -.28 & -.19 & $.48 *$ & .19 & -.06 \\
\hline Isolation & -.24 & .09 & -.06 & .32 & $.39 *$ & -.28 & .13 & -.01 \\
\hline
\end{tabular}

Walker

Factor $1 \quad-.08 \quad .27$

Walker

Eactor $2-. \emptyset 2-. \emptyset 1$

Walker $\quad-.08 \quad .30$

Total Pathology

* $=\mathrm{p}<05$

$\star \star=\mathrm{p}<\cdot \emptyset 1$

$\star \star \star=\mathrm{p}<. \emptyset \emptyset 1$ 
large proportion of the variance (i.e., 4l\%).

Conversely, male children who reportedly observed more marital discord at home were no more likely to be the object of aggression than other children in free-play settings.

A more modest relationship was found between male children's observations of marital discord at home and their initiation of aggression in observed free-play situations $\underline{r}(36)=.28, \underline{p}<.10$. A significant relationship was not found between these variables for females. Finally, no significant relationships were found between children's observation of marital discord and incidences of isolation in free-play situations or teacher and counselor ratings of acting-out, withdrawal, and total pathology on the walker Checklist for either gender.

To understand why counselors and teachers did not identify any behavioral differences between children coming from homes characterized by high versus low marital discord, the relationship between adult ratings on the walker Checklist and direct observations of children during free-play activities was examined separately for each gender. Since differences were found in the behavioral observations of children coming from homes characterized by discord, this analysis allowed for 
a comparison of observed and reported behavior. As expected, for males, there was a significant, positive relationship between ratings of acting-out and aggression on the wa.ker Scale, and observed aggression displayed on the playground. Male children who received higher ratings on Factor 1 of the walker scale (Acting-out/Aggression) were more likely to be the object of aggression, $\underline{r}(36)=.35, \underline{p}<.05$, and to aggress against other children, $\underline{r}(36)=.40, \underline{p}<.05$. Significant correlations between observed isolation and ratings of withdrawal were also found $\underline{r}(36)=.39, \underline{p}<.05$. Males 10 were rated high on factor 2 (withdrawal) of the walker Checklist were more likely to be isolated on the playground, $\underline{F}(1,34)=6.06, \underline{p}<.95$. Thus, despite the fact that boys from discordant families were not identified by adult ratings, there was a clear, positive relationship between teacher ratings of th boys' behavior and independent behavioral obser ations of them. surprisingly, the relationship between adult ratings on the walker checklist and girls' behavior on the playground was not in the expected direction. Females who were rated high on factor 2 (withdrawal) of the Walker scale, were significantly more aggressive in freeplay settings, $\underline{r}(24)=.48, \underline{p}<.05$. No significant relationship was found between aggression on the 
playground and factor 1 (acting-out) on the walker scale or between isolation on the playground and factor 2 (withdrawal) on the Walker Checklist for girls. Thus, teacher/counselor ratings did not identify girls from homes characterized by discord and the relationship for girls between adult ratings and direct observations on the playgzound was also unrelated.

As a :oliow-up to the correlational analyses presented above, a polynomial regression statistic (Kleinbaum \& Kupper, 1978) was computed to determine the shape of the relationship between chilcren's observations of marital discord in the familial environment and the various dependent variables. The specific program used in the present analysis (i.e., BMD-P5R) computes the least sciare fit of a polynomial of the primary independent variable (i.e., children's exposure to various degrees of marital discord according to maternal report) to the various dependent variables (i.e., direct observations and teacher/counselor reports of children's behavior in external settings).

Insert Figure 1 about here

Relationships between marital discord and all dependent variables for males and females were tested separately up to the third degree polynomial to determine 
Eigure 1. Shape of the Relationship between Marital Discord and object of Aggression for Females.

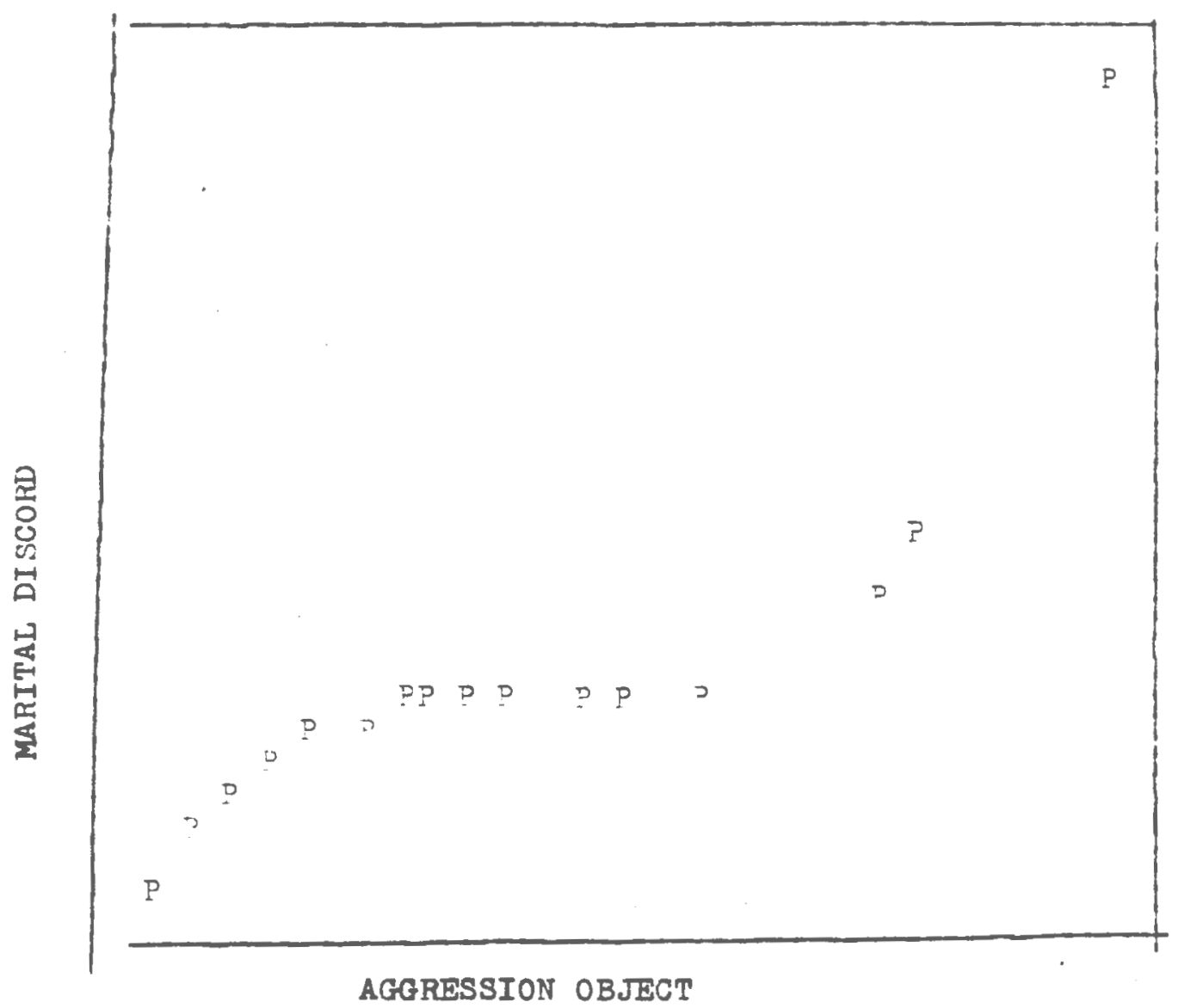


if a nonlinear model would add significantly to the variance explained. Significant results were found only between marital discord and being the object of aggression for females. The $R^{2}$ increased from .41 to .49, E2 $(2,21)=9.94, \underline{p}<. \emptyset \emptyset 1$ for the second degree and for the third degree went to $.57, \underline{E}(3,20)=8.73$, $\underline{p}<.001$. This change represents a $16 \%$ increase in explained variance. Thus, as depicted in Figure 1, the relationship between marital discord and being the object of aggression for females increased, leveled off slightly and increased again as the frequency of marital discord reported by the mother increased in the home.

Polynomial regressions were also calculated on the nonsignificant relationships found previously between the remaining independent and dependent variables. These analyses were conducted to determine whether the nonsignificant findings were due to nonlinear distributions in the data. For example, aggression i.: boys might have increased and decreased as marital discord increased. :owever, these relationships were also found to be nonsignificant. 


\section{Moderator Variables}

Partial correlations were computed to determine the influence of age, SES and IQ on the relationship bewween maternal ratings of marital discord in the familial environment and children's behavior outside of the home.

\section{Insert Table 6 about here}

As depicted in Table 6, these correlations indicate that the relationship between girls' behavior observed on the playground and marital discord remain significant when the effects of age, $\underline{r}(24)=65, \underline{p}<.091$ or IQ, $\underline{r}(24)=.66, \underline{p}<.001$ were removed. When the effects of SES were removed, this relationship decreased slightly, $\underline{r}(24)=.50, \underline{p}<.05$, but remained significant.

For boys, results of the partial correlation analysis indicated a nonsignificant relationship between marital discord and boys' behavior observed on the playground when the influence of age, IQ, or SES was partialled out. Thus, these variables did not affect the nonsignificant relationship previously found between boys' behavior and marital discord.

As a follow-up evaluation, the male and female subsamples were divided at the mean for age and median for IQ and SES. Pearson product moment correlations 
Table 6

Partial Correlations Between Marital Discord and Observed Behavior and Adult Ratings

\begin{tabular}{|c|c|c|c|}
\hline & Total & Males & Females \\
\hline \multicolumn{4}{|l|}{ Aggression } \\
\hline Object & $.29 \star \star \star$ & .18 & $.64 \star \star \star$ \\
\hline $\mathrm{AGE}$ & & .17 & $.65 * \star \star$ \\
\hline SES & & .13 & $.5 \emptyset *$ \\
\hline IQ & & .17 & $.66 * \star \star$ \\
\hline \multicolumn{4}{|l|}{ Aggression } \\
\hline Initiated & .23 & .28 & .17 \\
\hline AGE & & .32 & .16 \\
\hline SES & & .25 & .12 \\
\hline IQ & & .29 & .31 \\
\hline Isolation & -.14 & -.24 & .99 \\
\hline $\mathrm{AGE}$ & & -.25 &.$\emptyset 9$ \\
\hline SES & & -.23 & .22 \\
\hline IQ & & -.23 & .22 \\
\hline Walker Factor 1 &.$- \emptyset \emptyset$ & -.08 & .27 \\
\hline $\mathrm{AGE}$ & & -.13 & $.3 \emptyset$ \\
\hline SES & & -.13 & .29 \\
\hline IQ & & -.07 & .26 \\
\hline walker Factor 2 & -.02 &.$- \oslash 2$ & -.01 \\
\hline AGE & & -.11 & -.02 \\
\hline SES & &.$- \emptyset 2$ & -.08 \\
\hline IQ & & -.01 & .03 \\
\hline
\end{tabular}


were computed within each group between children's walker scores including Factor 1 and 2 and th. Total Pathology score and their mothers' ratirr: "marital discord. Correlations were also obtained between the behaviors of the children's free-play behaviors and marital discord for each group. The correlations are presented in Tables 7 and 8 .

Insert Table 7 and 8 about here

A significant, positive relationship was found between maternal reports of marital discord in the familial environment and being the object of other children's aggression in free play settings for girls. This relationship was apparen = in all groups of age and IQ, and in the lower SES bra aket. Thus, age and intelligence levels did not appear to differentially affect the relationship between marital discord and girls' behavior. Conversely, when the subsample of girls was divided into high and low socioeconomic status, the relationship between the observation of marital discord in the familial environment and being the object of other children's aggression in free-play settings was apparent only in the lower ses bracket.

In examining the effects of moderator variables for boys, significant, positive relationships were found that 
Table 7

Pearson Product Moment Correlations between Marital Discord and Male's Behaviors and Ratings on the

Walker Checklist divided into groups of Age, IQ, and SES

$$
\text { Males } \mathrm{N}=36
$$

$\underline{\mathrm{AGE}}$

$\underline{\text { IQ }}$

SES

Mean $\mathrm{H}(11) \quad \mathrm{L}(8) \quad \mathrm{H}(123) \quad \mathrm{L}(98.5) \quad \mathrm{H}(1-2) \quad \mathrm{L}(3-4)$

Aggression

Initiated

.08

$.57^{\star}$

$-.34$

.44 *

.28

.25

Aggression

object

.03

$.32-.29$

.25

$.22-.17$

Isolation

$$
-.42
$$

$-.17$

$-.11$

$-.25$

$-.28-.14$

Walker

$$
-.34
$$

$-.07$

$-.41$

.09

$-.18-.06$

Walker

$$
-.15-.13
$$

.01

.01

$-.02-.04$

Total

$$
-.42
$$

$-.99$

$-.36$

.06

$-.21$

.11

$*=\mathrm{p}<.05 ; \quad * *=\mathrm{p}<.01 ; * *=\mathrm{p}<.0 \emptyset 1$ 
Table 8

Pearson Product Moment Correiations between Marital

Discord and Feme" Behaviors and Ratings on the walker

Checklist divid. _o groups of Age. IO, and SES

Females $\mathrm{N}=24$

AGE

IQ

SES

\begin{tabular}{|c|c|c|c|c|c|c|c|}
\hline Mean--H & (1 & $0.6)$ & $L(8.5)$ & $\mathrm{H}(117)$ & L $(93) \quad H$ & $(1-2)$ & L $(4-5)$ \\
\hline Aggres & on & & & & & & \\
\hline Initiat & d & $.4 \emptyset$ & .18 & .18 & .07 & .08 & .15 \\
\hline Aggress & $\therefore \mathrm{n}$ & & & & & & \\
\hline object & & $.83 * * *$ & $.60 *$ & $.73 *$ & $.74 * *$ & $.69 \star \star \star$ & .26 \\
\hline Isolati & on & -.05 & .23 & .31 & .16 & .909 & .36 \\
\hline $\begin{array}{l}\text { Walker } \\
\text { Factor }\end{array}$ & 1 & .37 & .14 & .23 & .21 & .37 & .04 \\
\hline $\begin{array}{l}\text { Walker } \\
\text { Factor }\end{array}$ & 2 & .30 & -.48 & -.20 & .10 & .97 & -.31 \\
\hline $\begin{array}{l}\text { Total } \\
\text { Walker }\end{array}$ & Sco & $r e^{.34}$ & .27 & .41 & .02 & .24 & .03 \\
\hline
\end{tabular}

$\star=p<. \emptyset 5, \quad \star \star=p<. \emptyset 1, * \star \star=p<.0 \emptyset 1$ 
were not apparent in the preceeding analyses. For example, the relationship between maternal reports of observed marital discord in the familial environment and the frequency of aggression initiated toward other children in free-play settings was significant for younger boys, $\underline{r}(16)=.57, \underline{p}<.05$, and for those with lower intelligence, $\underline{r}(23)=.44, \underline{p}<.05$. Thus, materna? + ings of higher marital discord in the familial environment were associated with increased aggression with peers in these subgroups of boys. 


\section{Discussion}

The primary purpose of the present investigation was to examine the relationship of a child's observing marital discord in the familial environment with independent observations and ratings of the child's behavior in free-play settings. The obtained results suggest that the observation of marital discord by children in the familial environment is related to independent observations of some aspects of their behavior in free-play settings. Moreover, this relationship appears to depend upon the child's gender, age, intelligence and socioeconomic status.

The hypothesis that parental discord in the home differentially affects boys and girls observing it was supported in some aspects but not in others. For males, the predictions were partially supported. The behavior of male children who reportedly observed low to moderate rates of marital discord at home appeared to be differentially affected depending on a number of factors. For example, younger (6.1 to 9.8 years) and less intelligent (IQ< 108) boys in the present sample evidenced significantly more behavior problems in free-play situations compared to their peers. As predicted, these problems were typically characterized by increases in aggression towards others (i.e., problems of 
undercontrol). Curiously and contrary to prediction, these same subsamples of male children (i.e., younger or less intelligent) did not evidence significantly higher rates of behavior problems according to the teacher and counselor ratings. This finding is generally consistent with a recent investigation of a nonclinic sample (Emery \& O'Leary, 1984) where only a modest relationship was found between teacher ratings of children's behavior and marital discord.

The apparent discrepancy in results between the direct observations and adult ratings of children's behavior may be due to several factors. For example, structured classrooms and activities may limit the opportunity for social interactions (Asher \& Hymel, 1981) and consequently decrease the likelihood that children will exhibit aggressive behavior in these situations. Thus, the adult raters in the present investigation may have based t : r observations on the children's behavior during the more structured and directly supervised situations. This explanation appears supported as a majority of teachers and/or counselors did not participate directly or observe the children during free-play acivities (i.e., different adults were often responsible for the children at these times). Similarly, the discrepancy between adult ratings and 
direct observations of children's behavior may have been due to the specific situation and/or setting variables themselves. For example, unstructured play activity frequently involved a greater amount of physical contact and social interchange compared to structured sports activities and classroom situations, wherein the children were expected to stay seated and/or follow rules a majority of the time. Thus, children may have been exhibiting a normally expected increase in their rate of social interchange and aggressiveness.

Although the above explanations may account for the greater setting- and- observer-rated frequencies of aggressive behavior in general, neither adequately explains why only particular subsets of children (i.e., younger or less intelligent males coming from homes of low to moderate levels cf marital discord) were affected.

A more likely explanation is that children's display of overt aggressive behavior is subject to developmental changes as reported in previous investigations, with gradual decreases associated with maturity (Moore \& Muklai, 1983). Younger and less intelligent children may have fewer coping strategies and/or be more impressionable than older and brighter children. In the present investigation, however, significantly higher rates of aggressive behavior were found only when marital 
discord and either age (younger) or intelligence (lower) were accounted for in males. Thus, it appears that marker variables such as age and intelligence may differentially influence the behavior of male children when specific stressors are pratent in the familial environment (e.g., low to moderate levels of marital discord), and these effects tend to be situation and/or setting specific.

The observation of marital discord in the familial environment by female children was related to significantly higher rates of being the object of per aggression in free-play situations. Moreover, this relationship was apparent only in females coming from homes of lower socioeconomic status and was not associated with either age or intelligence. Similar to the male subsample of children reported above, teacher and counselor behavioral ratings were unrelated to maternal reports of marital discord.

Contrary to previous investigations (Block et al., 1981; Whitehead, 1979), and initial predictions, no: rer the adult ratings nor direct observations of female children in the present investigation revealed a discernible relationship between problems of withdrawal and isolation and marital discord. Instead, the difficulties exper: snced by female children from homes 
characterized by marital discord and lower socioeconomic status described herein, appeared to be claracteristic of more subtle and less overt problems. This explanation appears to be congruent with the findings of several recent investigations. For example, children (Wolfe, Zak, wilson, \& Jaffe, 1986) and female children in particular (Emery \& O'Leary, 1984) who have been exposed to familial violence and marital. discord, respectively, tend to exhibit significantly more problems with social competence and immaturity than their peers.

The results of the present and past investigations are more coherent if exposure to familial discord is viewed as a continuum. For example, it may be that exposure to extreme levels of marital discord (e.g., clinic populations) result in children responding with definitive problems of over and undercontrol, whereas lower levels (e.g., non-clinic populations) are assiciated with relatively few observable difficulties unless additional stressors (e.g., lower intelligence, SES, and agel are present. Our additional analyses (i.e., polynomial regressions) tend to support this contention in the female sample of children. The frequency or severity of discord present in the familial environment was associated with an increased likelihood of female children becoming the target of 
peer aggression. This relationship appears to stabilize at the intermediate range of reported discord, then increases as one approaches the upper end of the continuum studied in the present sample. In males, no relationship between boys' behavior and marital discord was observed except in the younger and less intelligent subsamples.

The gender-related differences found in this investigation are highly consistent with the modeling and family violence literature. For example, children are clearly influenced by the behavior of adult models in their immediate environment (Bandura, 1973) and are more likely to model the behavior of the same sex parent (Bandura, 1969). Similarly, exposure to familial violence as a child is frequently associated with an increased likelihood that males will perpetrate and females will be victimized in their adult relacionships (Gelles, 1976). The present investigation tends to support this general pattern of exposure and learning and suggests that this pattern emerges early in a child's development and can be observed in their peer relationships.

Einally, the present investigation highlights the importance of including direct observational data of child behavior in evaluating children coming from homes 
characterized by low to moderate levels of marital discord. Teacher ratings may be more salient and sensitive to children's behavioral disturbances at the extreme upper ends of the continuum (walker, 1983), yet fail to detect more subtle problems at the lower end of the distribution. Observation of children's social interaction n unstructured situations may prove to be a more valuable tool in this regard.

In future investigations, identifying the specific sociai antecedents which result in males being more aggressive and females being the object of aggression is needed. This information could be vital in intervening and changing behavioral patterns in children and reducing the frequency of marital discord ir subsequent generations. Careful attention to these issues is imperative to facilitate our understa aing of the complex factors affecting the relationshis, etween marital discord and children 3 behavioral : sturbances. 
Footnotes

1

An additonal question was also added to this questionnaire regarding the frequency of alcohol problems within the family. Only six of the 60 respondents indicated any problem in this area loccasionally 3 ; very Often 2; Often 1). Because of the low frequency, this item was not included in any further analysis. 2

Logarithmetic transformations also did not significantly increase the amount of variance explained. 


\section{REEERENCES}

Asher, S. R., \& Hymel, S. (1981). Children's social competence in peer relations: Sociometric and behavioral assessment. In J.D. Wine \& M.D. Smye (Eds.) Social Competence. New York: Guilford Press.

Bandura, A. (1969). Erinciples of Behavior Modification. New York: Holt, Reinhart \& Winston.

Bandura, A. (1973). Aggression: A Social Learning Analysis. Englewoo d Cliffs, N.J., Prentice-Hall.

Block, J., Block, J., \& Morrison, A. (1982). Parental aggreement-disagreement on child rearing orientations and gender related personality correlates in children. Child Development, 52, 965-974.

Brown, M. B., \& Forsythe, A. G. (1974). Robust tests for equality of variance. Journal of American Statistical Association, 69, 364-367.

Christensen, A., Phillips, S., Glasgow, R. E., \& Johnson, S. M. (1983) Parental characteristics and interpersonal dysfunction in families with child behavior problems: A preliminary investigation. Journal of Abnormal Child Psychology, 11(1) 153-166.

Cummings, M. E., Iannotti, R. J., \& Zahn-Waxler, C. $(1985)$. Influence of conflict between adults on the emotions of aggressive young children. Developmental Psychology, 12(3), 495-507.

Dunn, F. L., \& Dunn, J. (1981). Peabody Picture Vocabulary Test Manuel-Revised. Minneapolis: American Gu idance Service.

Emery, R. E. (1982). Interparental conflict and the children of discord and divorce. Psychology Bulletin, 92 (2) $31 \emptyset-33 \emptyset$.

Emery, R. E. \& O'Leary, D.K. (1984). Marital discord and child behavior problems in a nonclinic sample. Journal of Abnormal Child Psychology, 12(3), 411-420.

Emery, R. E., Weintraub, S., \& Neale, J. (1982). Effects of marital discord on the school behavior of schizophren: $z$, affectively disordered and normal 
parents. Journal of Abnormal Child Esychology, 10 (21), $215-228$.

Fergerson, L. R., \& Allen, D. R. (1978). Congruence of parent perception, marital satisfaction, and child adjustment. Journal of Consulting and Clinical Psychology, $4 \bar{\emptyset}, 345-3 \overline{46}$.

Gelles, R. (1976). Family Violence. Bever y Hills, CA: Sage.

Griest, D. L., Eorehand, R., Wells, K. C., \& McMahan, R.J. (1980). An examination of di ferences between nonclinical and behavior-problem $c+$ inic-referred children. Journal of Abnormal Esychology, 89, 497-500.

Hetherington, E. M. (1972). Effects of father absence on personality development in adolescent daughters. Developmental Psychology, 313-326.

Hollingshead, A. (1957). Two Eactor Index of Social position. Unpublished manuscript, Yale University.

Johnson, S. M., \& Lobitz, C. K. (1974). The personal and marital adjustment of parents as related to observed child deviance and parenting behavior. Journal of Abnormal Child Psychology, 2, 193-207.

Kalmuss, D. (1984). The intergenerational transmission of aggression. Journal of Marriage and the Family, 11-19.

Kazdin, A. (1982) Single Case Resarch Design Methods for Clinical and Applied Settings. New York: Oxford University Press.

Lerner, R. M., \& spanier, G. B. (1978). Child Influences on Marital and Family Interaction: A Life-span Perspective. New York: Academic Press.

Lock, H., \& Wal-ace; K. (1959). Short Marital adjustment and prediction tests: Their reliability and validity. Marriage and Family Living 21, 251-255.

Margolin, G. \& Patterson, G. R. (1975). Differental consequences provi $7 \mathrm{e}$ by mothers and fathers for their sons and daughters, Developmental Psychology 11, 537538 . 
Mash, E., \& Mercer,B.J. (1979). A comparison of the behavior of deviant and non-deviant boys while playing alone and interacting with a sibling, Journal of Child Psychology and Psychiatry, 20, 197-204.

Moore, D. K., \& Muklai, L. H. (1983). Aggressive behavior in the home as a function of the age and sex of conduct problem and normal children, Journal of Abnormal Child Psychology, 11, 257-272.

Oltmanns, T., Broderick, J., \& O'Leary, K. D. (1977). Marital adjustment and the efficacy of behavior therapy with children. Journal of Consulting and clinical

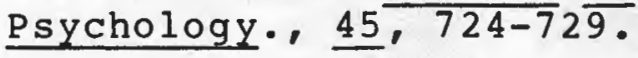

O'Leary, K. D., \& EmerY, R. (1983). Marital discord and Child Behavior Problems. Paper presented at Middle Childhood symposium, New orleans, Louisana, January,16, 1983.

Owens, D.M., \& Straus, M.A. (1975). The Social structure of violence in childhood and approval of violence as an adult. Aggressive Behavior., I (2), 193-211.

Porter, B. (1981). Parental behavior and feelings in distressed and nondistressed marriages. Unpublished doctoral dissertation, State University of New York at stony Brook.

Porter, B., \& O'Leary, K.D. (1980). Types of marital discord and child behavior problems. Journal of Abnormal Child Psychology, 8, 287-295.

Rosenthal, R. (1966). Experimenter Bias in Behavior Research. New York: Appleton-Centery-Crofts.

Rutter, M. (1970). Sex differences in response to family stress. In E. J. Anthony \& C. Kouplinic (Eds) The Child and his Family. New York: Wiley.

Rutter, M. (1971). Parent-child separation: Psychological effects on the children, Journal of Child Psychology and Psychiatry, 12, 233-260.

Rutter, M. (1980). Protective factors in children's response to stress and disadvantage. In M. W. Kent \& J. E. Rolf (Eds) Primary Prevention of Psychopathology I : Promoting social Competence and coping in Children (pp. 49-74). Hanover, New Hampshire: University Press 
of New England.

Rutter, M., Yule, B., Quinton, D., Rowlands, D., Yule, W. \& Berger, M. (1975). Attainment and adjustment in two geographic areas: Some factors accounting for area differences. British Journal of Psychiatry, 126, 520533 .

Straus, M.A., (1978). Wife Beating: How Common and Why? Victimology: An International Journal, $2(3-4), 443-$ 458 .

Walker, H. M. (1983) The Walker Problem Identification Checklist-Revised. $\overline{L O S}$ Angles, CA: Western Psychological Services.

Walker, H. M., \& Buckley, N. (1973). Eree operant teacher attention to deviant child behavior after treatment in a special class. Psychology in the Schools, 8, 275-284.

Walker, H. M., \& Hops, H. (1979). The CLASS program for acting-out children: $R \& D$ procedures, program outcomes, and implementation issues. School psychology Digest, $8,370-381$.

Whitehead, L. (1979). Sex differences in children's response tdo family stress: A re-evaluation. Journal of Child Psychology and Psychiatry, 20, 247-254.

Wolfe, D.A., Zak, L., Wilson,S., \& Jaffe, P. (1986).

Child witnesses to violence between parents: Critical issues in behavioral and social adjustment. Journal of Abnormal Child Psychology, 14, 95-104. 
SECTION I I 
Appendix A

Modeling is a means by which marital discord may affect children. In a discordant marriage, parents may model aggression and hostility as methods of handling conflict in the presence of the children lowens \& Straus, 1975) Bandura (1973) suggests that children can learn aggression by observing their parents and subsequently directly imitate or counterimitate this behavior (i.e., do exactly the opposite of what the parent models). According to Bandura's social learning theory, aggressive models not only provide examples for learning, but may subsequently reduce the observer's inhibition in displaying aggression.

Modeling explanations of sex differences in response to marital discord are numerous. The strongest effects of modeling are typically produced when they are combined with postive reinforcement. For example, Bandura (1969) found that parents of aggressive boys consistently modeled agcression in their Erequent use of verbal and physical punishment of their shildren. These parents also consisten ly Junished gression directed toward themselves, but encol : intermitiantly reinforced aggression outsi..e tha home.

Gender differences might also be expected to occur in children who observe $m$ : tal aggression at home due to 
the way in which modeling occurs. According to Bandura, children are more likely to model the behavior of the same sex parent. Since it is likely that husbands act more overtly and severely aggressive than wives during times of marital discord, (straus, 1978) differential imitation of this interaction might lead to gender differences in the chicacen who observe this. 
APPENDIX B

The Peabody Picture Vocabulary Test-Revised (PPVT-R)

The Peabody Pictu e Vocabulary Test-Revisec (PPVT-R) is an individually alministered, norm-referen zed, wide-range test of receptive vocabulary. It consist; of 175 test items arranged in order of increasing difficulty. Each item has four simple, black-and-white illustrations arranged in a multiple-cnoice format. The subject's task is to select the picture considered to illustrate best the meaning of a stimulus word presented orally by the examiner .

The test is designed for persons $21 / 2$ through $4 \emptyset$ years of age. It was standardized nationally on a sample of $5, \emptyset 28$ persons- $4,29 \emptyset$ children and adolescents, and 828 aduits. Raw scores are converted to age-referenced norms. The PPVT-R has been shown to have good testretest reliability for children ranging from .71 to .89 with a median of .79 . It correlates moderately with the Wechsler Scales of Intelligence and the Stanford-Binet Test of Intelligence. 
APPENDIX C

\section{The o'Leary Porter Scale}

The O'Leary-porter Scale was devised as a face-valid meaure of openly exfressed marital discord in the home. It consists of 10 items ( 9 scored and 1 unscored), items. Scored items contain questions coneerning how often various forms of marital hostility occur in front of the child. Parents are asked to rate each item on a 5 point scale from never to very often.

The O'Leary-Porter scale has been shown to have high internal consistency and test-retest reliability of .96 over a two wek period. It is moderately correlated with the Short Marital Adjustment Test $(r=.63)$ (Porter \& O'Leary, 1989$)$. 
APPENDIX D

\section{The Hollingshead Two Factor Index of Social Position}

The Hollingshead Two Eactor Index of Social Position is a modified form of the Alba Edwards system of classifying occupations into socioeconomic groups employed by the U.S. Bureau of the census. The scale used in the Index of Social position ranks professions into different groups and businesses according to their size and value. The seven positions on the modified scale are: (1) executives and proprietors of large concerns and major professionals; (2) managers and proprietors of medium concerns and minor professionals; (3) administrative personnel of large concerns, owners of small independent businesses, and semiprofessionals; owners of little businesses, clerical and sales workers, and technicians; (5) skilled workers; (6) semiskilled workers; and (7) unskilled workers.

The educational scale is premised upon the assumption that people who posses similar educations tend to have similar tastes and attitudes and tend to exhibit similar behavior patterns. Tr: educational scale is divided into seven positions: (1) graduate professional training (persons who completed a recognized course which led to the receipt of a graduate degree); (2) standard college or university graduation; (3) partial college 
train: g; (4) high-school graduation; (5) partial high schoo:; (6) junior high school; (7) less than seven years of school.

To calculate the Index of Social Position score for an individual, the scale value for occupation, and the scale value for education is multiplied by the factor weight for education as follows:

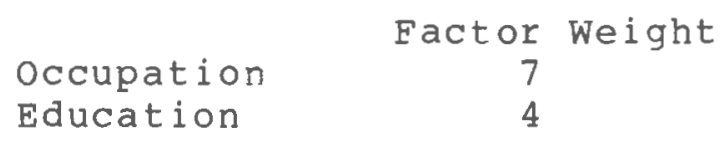

The Two Factor Index of Social Position scores may be arranged on a continuum or divided into groups of scores as follows:

$11-17$ Social Class

18-27

I

I I

$28-43$

$44-6 \emptyset$

$61-77$

I I I

IV

V 
APPENDIX E

The Walker Problem Behavior Icentification Checklist (Revised 1983)

The Walker Problem Identification Checklist (WPBIC)

is an assessment tool for the elementary teacher in

identifying children with behavior problems and

disorders. It is composed of $5 \emptyset$ descriptions of

observerble, maladaptive behaviors whica were generated

through interviews with elementary school teachers. The checklist, intended for use in preschool (ages 2 to 5), kindergarten, and grades 1 through 6 , measures problem behaviors in five areas: Acting out, withdrawal, Distractibility, Disturbed Peer Relations, and Immaturity. In addition to scores for each of these areas, a Total score is derived to provide a measure of overall behavioral ....tioning.

The WPBIC was : med on samples of preschool/ kindergarten, primary and intermediate students. Separate T-score distributions by sex are available for each sample. It has adequate test-retest reliability. Total score stability coefficients approximate . $8 \emptyset$ across separate studies and samples. Test-retest coefficients for the separate scale of Acting out were .88 and .76 for withdrawal (Walker \& Bull, 197ø).

A strong empirical relationship has been demonstrated between teacher ratings on the WPBIC and 
parent ratings at home (Mash \& Mercer, 1979) and with observed behavior (walker \& Buckley, 1973). 


\section{APPENDIX F}

\section{Parent Letter}

Dear Parents:

one of my graduate students, Dorothy clement, is studying a very important subject matter for her dissertation: family relationships and their effect on children'e behavior. Although many people have speculated about the impact parents have on their children, there is very little concrete evidence on this topic.

We are gratefully requesting your assistance in this endeavor. If you choose to help us, please complete the enclosed questionnaire in response to your child attending child in the envelope provided sealed. This questionnaire is being sent home to the families of third, fourth, fifth, and sixth graders. Your complete questionnaire and signed permission slip will allow us (a) to have your child's teacher complete a short behavior rating scale on your child's behavior and (b) to unobtrusively observe your child at play. Additionally, a brief intellectual assessment will be administered for those children participating in this project. Your child's intellectual assessment and age equivalent will not be made available to anyone except yourself on request.

In order to keep your responses completely confidential, we will be identifying your correspondence by number. Using this method, no names will be used and no school/camp official will be aware of your questionnaire response. Children s?lected to be observed will also be identified by number to further insire confidentiality.

$\therefore \quad$ ou choose to participate in this prciect, please return the questionnaire with your child enclosed envelope sealed. If you do not choose to ji.icipate in this project, please return the questionnaire unmarked in the envelope.

Thank you for your time and cooperation. I sincerely hope you will choose to participate in this important project and help us better understand children's behavior.

Wit: best regards, Mark D. Rapport Ph.D. Assistant Professor 
APPENDIX G

Coded Data sheet

Observer

Camp/school

Child's Name

Date:

Ao=Aggression (The object) Ai=Aggression (The initiator) $I$ I solation $\quad 0=$ other

$\begin{array}{lllllllll}1 & 2 & 3 & 4 & 5 & 6 & 7 & 8 & 9\end{array}$ AO Ai AO Ai AO Ai AO Ai AO Ai AO Ai AO $\because$ AO Ai AO Ai $\begin{array}{llllllllllllllllll}I & 0 & I & 0 & I & 0 & I & 0 & I & 0 & I & 0 & I & 0 & I & 0 & I & 0\end{array}$ AO Ai AO Ai AO Ai AO Ai AO Ai AO Ai AO Ai AO Ai AO Ai $\begin{array}{llllllllllllllllll}I & 0 & I & 0 & I & 0 & I & 0 & I & 0 & I & 0 & I & 0 & I & 0 & I & 0\end{array}$ AO Ai AO Ai AO Ai AO Ai AO Ai AO Ai AO Ai AO Ai AO Ai $\begin{array}{llllllllllllllllll}I & 0 & I & 0 & I & 0 & I & 0 & I & 0 & I & 0 & I & 0 & I & 0 & I & 0\end{array}$ AO Ai AO Ai AO Ai AO Ai AO Ai AO Ai AO Ai AO Ai AO Ai $\begin{array}{llllllllllllllllll}I & 0 & I & 0 & I & 0 & I & 0 & I & 0 & I & 0 & I & 0 & I & 0 & I & 0\end{array}$ AO Ai AO Ai AO Ai AO Ai AO Ai AO Ai AO Ai AO Ai AO Ai $\begin{array}{llllllllllllllllll}I & 0 & I & 0 & I & 0 & I & 0 & I & 0 & I & 0 & I & 0 & I & 0 & I & 0\end{array}$ AO Ai AO Ai AO Ai AO Ai AO Ai AO Ai AO Ai AO Ai AO Ai $\begin{array}{llllllllllllllllll}I & 0 & I & 0 & I & 0 & I & 0 & I & 0 & I & 0 & I & 0 & I & 0 & I & 0\end{array}$ AO Ai AO Ai AO Ai AO Ai AO Ai AO Ai AO Ai AO Ai AO Ai $\begin{array}{llllllllllllllllll}I & 0 & I & O & I & 0 & I & 0 & I & 0 & I & 0 & I & 0 & I & 0 & I & 0\end{array}$ AO Ai AO Ai AO Ai AO Ai AO Ai AO Ai AO Ai AO Ai AO Ai $\begin{array}{llllllllllllllllll}I & 0 & I & 0 & I & 0 & I & 0 & I & 0 & I & 0 & I & 0 & I & 0 & I & 0\end{array}$ Ao Ai AO Ai AO Ai AO Ai AO Ai AO Ai AO Ai AO Ai AO Ai $\begin{array}{llllllllllllllllll}I & 0 & I & 0 & I & 0 & I & 0 & I & 0 & I & 0 & I & 0 & I & 0 & I & 0\end{array}$ AO Ai AO Ai $F$, Ai AO Ai AO Ai AO Ai AO Ai AO Ai AO Ai $\begin{array}{lllllllllllllllll}I & 0 & I & 0 & 0 & I & 0 & I & 0 & I & 0 & I & 0 & I & 0 & I & 0\end{array}$ AO Ai AO Ai AO Ai AO Ai AO Ai AO Ai AO Ai AO Ai AO Ai $\begin{array}{llllllllllllllllll}I & 0 & I & 0 & I & 0 & I & 0 & I & 0 & I & 0 & I & 0 & I & 0 & I & 0\end{array}$ AO Ai AO Ai AO Ai AO Ai AO Ai AO Ai AO Ai AO Ai AO A: $\begin{array}{llllllllllllllllll}I & 0 & I & 0 & I & 0 & I & 0 & I & 0 & I & 0 & I & 0 & I & 0 & I & 0\end{array}$ 